\title{
Modeling Single-Phase Inverter and Its Decentralized Coordinated Control by Using Feedback Linearization
}

\author{
Renke Han, Qiuye Sun, Dazhong Ma, and Bonan Huang \\ Department of Electrical Engineering, Northeastern University, Wenhua Road 3-11, P.O. Box 134, Shenyang 110819, China \\ Correspondence should be addressed to Qiuye Sun; sunqiuye@ise.neu.edu.cn
}

Received 22 June 2014; Accepted 12 September 2014; Published 9 October 2014

Academic Editor: Teh-Lu Liao

Copyright ( 2014 Renke Han et al. This is an open access article distributed under the Creative Commons Attribution License, which permits unrestricted use, distribution, and reproduction in any medium, provided the original work is properly cited.

\begin{abstract}
It is a very crucial problem to make a microgrid operated reasonably and stably. Considering the nonlinear mathematics model of inverter established in this paper, the input-output feedback linearization method is used to transform the nonlinear mathematics model of inverters to a linear tracking synchronization and consensus regulation control problem. Based on the linear mathematics model and multiagent consensus algorithm, a decentralized coordinated controller is proposed to make amplitudes and angles of voltages from inverters be consensus and active and reactive power shared in the desired ratio. The proposed control is totally distributed because each inverter only requires local and one neighbor's information with sparse communication structure based on multiagent system. The hybrid consensus algorithm is used to keep the amplitude of the output voltages following the leader and the angles of output voltage as consensus. Then the microgrid can be operated more efficiently and the circulating current between DGs can be effectively suppressed. The effectiveness of the proposed method is proved through simulation results of a typical microgrid system.
\end{abstract}

\section{Introduction}

More and more AC and DC distributed generations (DGs) are connected to the systems which requires more flexible and modular control systems. Hence, microgrids can play this role when mass grid independency is unfitted. In a microgrid, DGs are controlled to deliver desired power to the system; meanwhile, to minimize circulating current is another important control objective in order to keep microgrid be operated stably. In general, many control methods for such a microgrid system are proposed which can be categorized as centralized control $[1,2]$ and decentralized control [3-6]. Both of the two control methods are based on the conventional droop control [7-10].

The centralized control requires a complex communication network with two-way communication that can adversely affect the stability of the system. The droop control achieves the active and reactive power being shared proportionally by controlling system frequency and fundamental voltage amplitudes conventionally [11]. Since no communication is needed between inverters by this method, it is attractive. However, the conventional droop controller has several drawbacks that limit its application area, such as loaddependent frequency and deviation of voltage amplitude, high dependency on the inverter output-impedance, and large circulating current between inverters [9, 12-14]. In [15], a strategy to improve the control technique is proposed by changing the droop coefficient and estimating the effect of the line impedance value. However, this strategy is quite complicated and sensitive [16]. Meanwhile, the conventional droop control is a linear method, but the inverter is a nonlinear model [10]; thus, the microgrid cannot be effectively controlled only by droop control. Thus, the nonlinear factors should be considered in the control method. The input-output feedback linearization is used to transform the nonlinear heterogeneous dynamics of DGs to linear system [17]. Meanwhile, in order to make power shared without deviation in either the frequency or the amplitude of the output voltage, some communication should also be added in the system.

Considering the above limitations, the decentralized coordinated control with minimal communication is an 
effective way to control DGs. Meanwhile, the distance between the inverters may make an intercommunication between all inverters impractical in a real system.

Recently, multiagent systems are extensively studied due to their flexibility and computational efficiency. The authors of [18] design the consensus algorithm considering an active leader agent followed by other agents. Considering that every DG unit is an agent in the multiagent system, the decentralized coordinated control with multiagent consensus protocol is used in this paper. In addition, because slight differences in phases and amplitudes of the inverters output voltages can cause large circulating currents [19], circulating currents are not well suppressed only by controlling the output voltage amplitude. A new droop control based on the angle of the output voltage, referred to as angle droop, is proposed and has more advantages than frequency droop control [20,21]. Thus, in order to regulate the angle and amplitudes of voltage at the same time to suppress the circulating currents, the angleactive droop control is used to combine with the reactivevoltage control in this paper. Then the amplitudes of output voltages are controlled by the leader consensus algorithm to track the leader's information which comes from one DG in the microgrid. Meanwhile, the angles of output voltages are controlled by the leaderless consensus algorithm to achieve the average consensus.

In this paper, hybrid multiagent consensus algorithm is used to address the tracking synchronization problem about amplitudes of output voltages and the consensus regulation problem about angles by using the input-output feedback linearization. This method is superior to the scalar control by which only amplitudes of the voltage are controlled. A decentralized coordinated controller based on angle-active power droop control and voltage-reactive power droop control is designed to make active and reactive power shared proportionally and suppress circulating currents between DGs. The multiagent consensus algorithm is used to calculate the deviation of angle and amplitudes between inverters by using the leaderless consensus algorithm and the leader consensus algorithm. Then the calculation results are used as the feedback values. The main contributions of this paper are given as follows.

(1) By using feedback linearization method combined with hybrid multiagent consensus algorithm, the power can be shared proportionally and the angles and amplitudes of output voltage can be kept consensus.

(2) By using hybrid multiagent consensus algorithm, the amplitude of output voltages and angles can be controlled more reasonably and economically.

(3) The control method requires only a sparse communication structure which can be more reliable.

(4) The circulating current between inverters can be effectively suppressed; thus, energy conservation and the stability operation of the microgrid can be achieved.

This paper is organized as follows. In Section 2, the dynamical model of single-inverter-based DGs is established.
Section 3 discusses the process of the combination of the input-output feedback linearization and hybrid multiagent consensus algorithm. Section 4 discusses the analysis of circulating current between parallel inverters. In Section 5, the effectiveness of the proposed method is verified by comparing simulation results of conventional control method and proposed control method. Section 6 concludes the paper.

\section{Nonlinear Model of Single-Phase Inverter}

The proposed control method is designed based on the large signal dynamical model of single-phase inverters in DGs. There are power calculation, voltage and current controllers, and second order generalized integrator in the control loops to adjust the amplitude and angle of output voltage. The control block diagram of a DG based on a single-phase inverter is presented in Figure 1.

Because the single-phase inverters are studied in this paper, the output voltage and current from inverters should be divided into the $\alpha-\beta$ components first by using a second order generalized as shown in Figure 2 [22].

The phase of output voltage from the $i$ th $\mathrm{DG} \delta_{i}$ can be expressed as

$$
\dot{\delta}_{i}=\omega_{i},
$$

where $\delta_{i}$ is the angle of voltage from $i$ th DG and $\omega_{i}$ is the frequency of $i$ th DG.

So, instead of using the common reference frame, regulating angles of output voltages can make the $d-q$ reference frames rotated synchronously.

There are second order generalized integrator, park transformation, power calculation, low-pass filter, and droop controller in the power controller shown in Figure 3. The power controller can provide the amplitude reference of voltage $v_{o d i}^{*}$ for the first stage bridge and the angle reference of output voltage $\delta_{i}^{*}$ for the second stage bridge. The $\theta_{\text {park }}$ which is used to make the park transformation is calculated by making the reference $v_{q}^{*} \equiv 0$. The instantaneous active and reactive power can be expressed as

$$
\begin{aligned}
& \widetilde{p}_{i}=\frac{\left(v_{o d i} i_{o d i}+v_{o q i} i_{o q i}\right)}{2}, \\
& \tilde{q}_{i}=\frac{\left(v_{o d i} i_{o q i}-v_{o q i} i_{o d i}\right)}{2},
\end{aligned}
$$

where $v_{o d i}$ and $v_{o q i}$ are $d$-q axis output voltage components for $i$ th DG, $i_{\text {odi }}$ and $i_{o q i}$ are $d-q$ axis output current components for $i$ th DG, and $\widetilde{p}_{i}$ and $\widetilde{q}_{i}$ are instantaneous active and reactive power for $i$ th DG.

The differential equations of the active and reactive power can be expressed as

$$
\begin{aligned}
& \dot{P}_{i}=-\omega_{c i} P_{i}+\omega_{c i} \widetilde{p}_{i}, \\
& \dot{Q}_{i}=-\omega_{c i} Q_{i}+\omega_{c i} \widetilde{q}_{i},
\end{aligned}
$$

where $P_{i}$ and $Q_{i}$ are the average active and reactive power for $i$ th DG and $\omega_{c i}$ is cutoff frequency of power filter. 


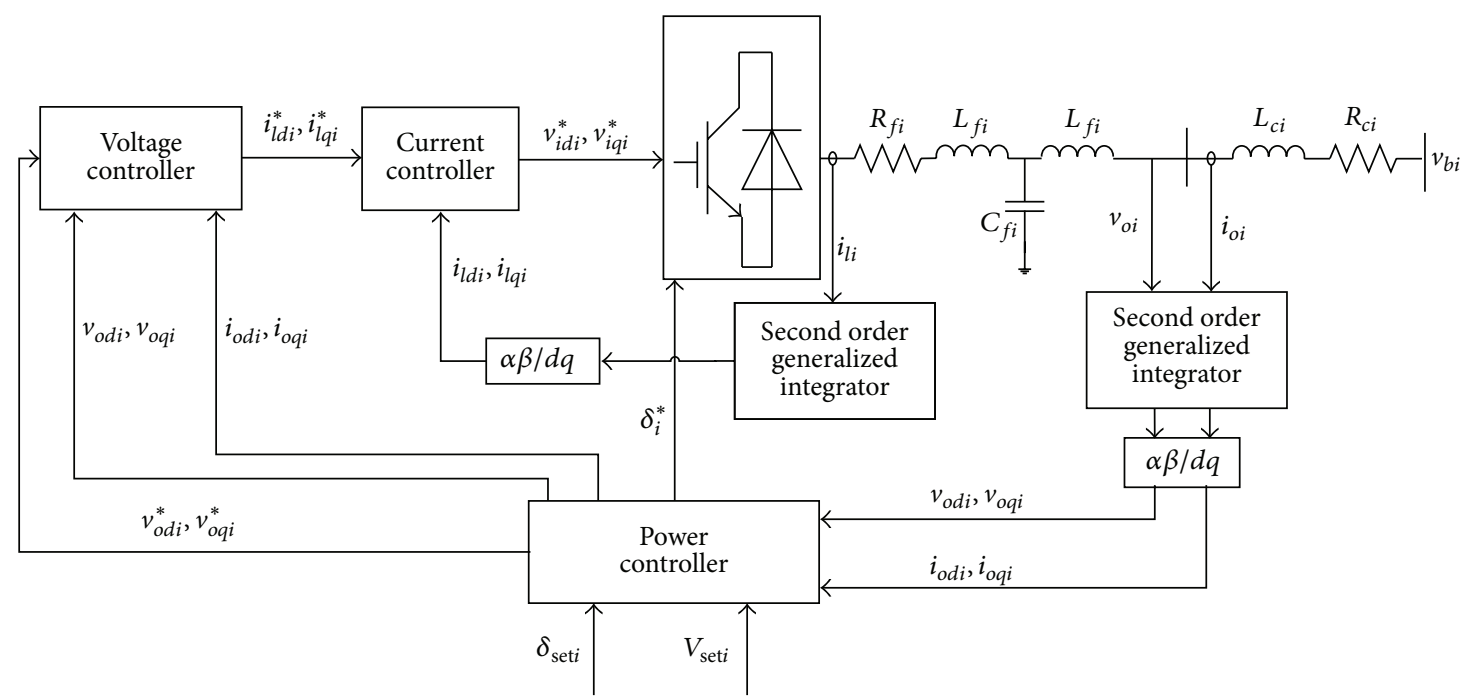

FIGURE 1: Block diagram of a DG based on a single-phase inverter.

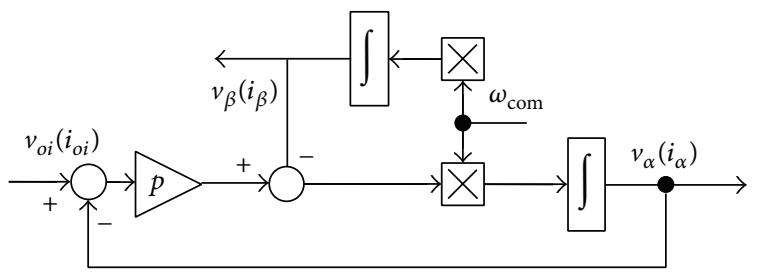

FIGURE 2: Second order generalized integrator.

The angle-active power and amplitude-reactive power droop controllers are presented as

$$
\begin{gathered}
P_{i}=\frac{1}{m_{i}\left(\delta_{\text {seti }}-\delta_{i}^{*}\right)}, \\
Q_{i}=\frac{1}{n_{i}\left(v_{\text {seti }}-v_{o d i}^{*}\right)}, \\
v_{o q i}^{*}=0,
\end{gathered}
$$

where $m_{i}$ is the angle-active droop parameter for $i$ th DG, $n_{i}$ is the voltage-reactive droop parameter for $i$ th DG, $\delta_{\text {set } i}$ is the set value of angle-active droop control for $i$ th DG, $v_{\text {set } i}$ is the set value of voltage-reactive droop control for $i$ th $\mathrm{DG}, \delta_{i}^{*}$ is the reference of voltage angle for $i$ th DG, and $v_{o d i}^{*}$ and $v_{o q i}^{*}$ are the $d-q$ axis reference of voltage amplitude in the voltage controller for $i$ th DG.

Equations (3) are inserted into (2) and it yields

$$
\begin{array}{r}
\dot{P}_{i}=\omega_{c i} \widetilde{p}_{i}+\frac{\omega_{c i}}{m_{i}\left(\delta_{i}^{*}-\delta_{\text {set } i}\right)}, \\
\dot{Q}_{i}=\omega_{c i} \widetilde{q}_{i}+\frac{\omega_{c i}}{n_{i}\left(v_{o d i}^{*}-v_{\text {set } i}\right)} .
\end{array}
$$

The block diagram of the voltage controller is shown in Figure 4. The input differential equations of the voltage controller are presented as

$$
\begin{gathered}
\dot{\phi}_{o d i}=v_{\text {set } i}-n_{i} Q_{i}-v_{o d i}, \\
\dot{\phi}_{o q i}=v_{o q i}^{*}-v_{o q i},
\end{gathered}
$$

where $\phi_{o d i}$ and $\phi_{o q i}$ are the $d$-q axis auxiliary state variables in the voltage controller for $i$ th DG.

Then the assist terms in the voltage controller are as follows:

$$
\begin{aligned}
& \mathrm{ASS}_{d i}=F i_{o d i}-\omega_{i} C_{f i} v_{o q i}, \\
& \operatorname{ASS}_{q i}=F i_{o q i}+\omega_{i} C_{f i} v_{o d i},
\end{aligned}
$$

where $F$ is the feedforward parameter in the voltage controller, $C_{f i}$ is the filter capacitor for $i$ th DG, and $\mathrm{ASS}_{d i}$ and ASS $_{q i}$ are the $d-q$ axis auxiliary variables used to be the decoupling terms and the feedforward terms.

The outputs of the voltage controller are presented as

$$
\begin{aligned}
& i_{l d i}^{*}=k_{p \operatorname{Vodi}}\left(v_{o d i}^{*}-v_{o d i}\right)+k_{i \operatorname{Vodi}} \phi_{o d i}+\mathrm{ASS}_{d i}, \\
& i_{\text {lqi }}^{*}=k_{q \text { Voqi }}\left(v_{o q i}^{*}-v_{o q i}\right)+k_{i \text { Voqi }} \phi_{o q i}+\mathrm{ASS}_{q i},
\end{aligned}
$$

where $i_{l d i}^{*}$ and $i_{l q i}^{*}$ are $d-q$ axis current reference in the current controller for $i$ th DG, $k_{p V o d i}$ and $k_{q V o d i}$ are the $d$-q axis proportion parameters in the voltage controller for $i$ th DG, and $k_{i V o d i}$ and $k_{i V o q i}$ are the $d-q$ axis integral parameters in the voltage controller for $i$ th DG.

The block diagram of the current controller is shown in Figure 5. The input differential equations of the current controller are presented as

$$
\begin{aligned}
& \dot{\gamma}_{d i}=i_{l d i}^{*}-i_{l d i}, \\
& \dot{\gamma}_{q i}=i_{l q i}^{*}-i_{l q i},
\end{aligned}
$$




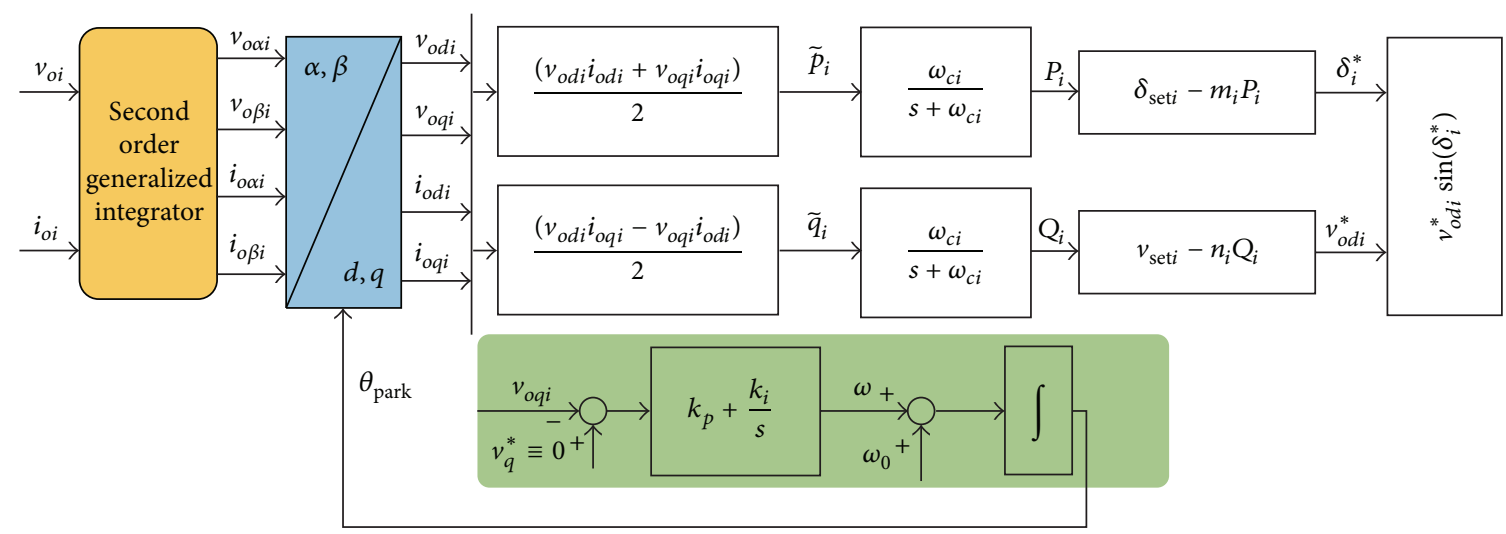

Figure 3: The block diagram of power controller.

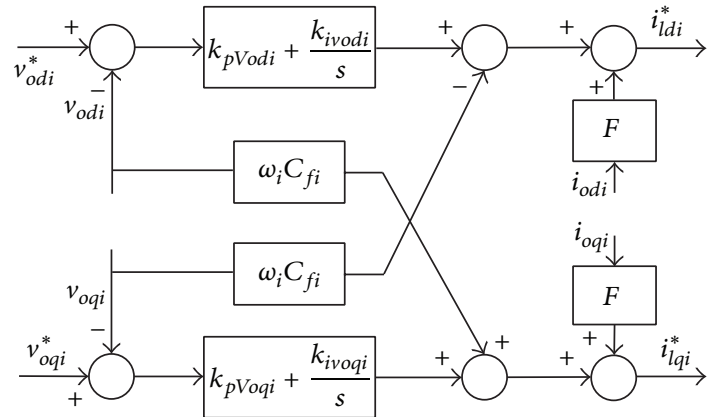

FIGURE 4: The block diagram of the voltage controller.

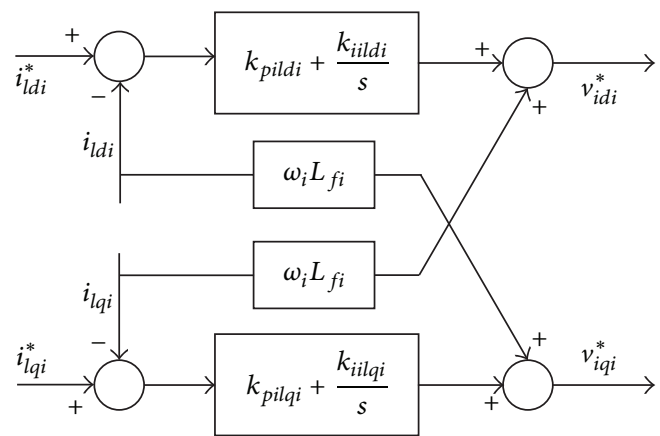

FIGURE 5: The block diagram of the current controller.

where $\gamma_{d i}$ and $\gamma_{q i}$ are the $d$-q axis auxiliary state variables in the current controller for $i$ th DG and $i_{l d i}$ and $i_{l q i}$ are the $d-q$ axis filter current components for $i$ th DG.

The outputs of the current controller are presented as

$$
\begin{gathered}
v_{i d i}^{*}=-\omega_{i} L_{f i} i_{l q i}+k_{p i l d i}\left(i_{l d i}^{*}-i_{l d i}\right)+k_{i i l d i} \gamma_{d i}, \\
v_{i q i}^{*}=\omega_{i} L_{f i} i_{l d i}+k_{p i l q i}\left(i_{l q i}^{*}-i_{l q i}\right)+k_{i i l q i} \gamma_{q i},
\end{gathered}
$$

where $v_{i d i}^{*}$ and $v_{i q i}^{*}$ are $d$ - $q$ axis output of current controller for $i$ th DG, $L_{f i}$ is the filter inductance for $i$ th DG, $k_{p i l d i}$ and $k_{\text {pilqi }}$ are the $d-q$ axis proportion parameters in the current controller for $i$ th DG, and $k_{\text {pildi }}$ and $k_{i i l q i}$ are the $d-q$ axis integral parameters in the current controller for $i$ th DG.
Assumption 1. The parameters in connection lines should meet the following conditions in (13) as shown in Figure 1. Both resistive and inductor in connected lines are considered [14]. Consider

$$
\begin{aligned}
& L_{c 1} \approx L_{c 2} \approx \cdots \approx L_{c n}, \\
& R_{c 1} \approx R_{c 2} \approx \cdots \approx R_{c n},
\end{aligned}
$$

where $L_{c i}$ and $R_{c i}$ are the line parameters in the microgrid.

The differential equations for the output LCL filter and output connector considering the $R-L$ line parameters are as follows:

$$
\begin{gathered}
\dot{i}_{l d i}=-\frac{R_{f i}}{L_{f i}} i_{l d i}+\omega_{i} i_{l q i}+\frac{1}{L_{f i}}\left(v_{i d i}-v_{o d i}\right), \\
\dot{i}_{l q i}=-\frac{R_{f i}}{L_{f i}} i_{l q i}-\omega_{i} i_{l d i}+\frac{1}{L_{f i}}\left(v_{i q i}-v_{o q i}\right), \\
\dot{v}_{o d i}=\omega_{i} v_{o q i}+\frac{1}{C_{f i}}\left(i_{l d i}-i_{o d i}\right), \\
\dot{v}_{o q i}=-\omega_{i} v_{o d i}+\frac{1}{C_{f i}}\left(i_{l q i}-i_{o q i}\right), \\
\dot{i}_{o d i}=\omega_{i} i_{o q i}+\frac{1}{L_{c i}}\left(v_{o d i}-v_{b d i}\right)-\frac{R_{c i}}{L_{c i}} i_{o d i}, \\
\dot{i}_{o q i}=-\omega_{i} i_{o d i}+\frac{1}{L_{c i}}\left(v_{o q i}-v_{b q i}\right)-\frac{R_{c i}}{L_{c i}} i_{o q i} .
\end{gathered}
$$

From (1), (7)-(8), (11), and (14), the model of $i$ th DG can be rewritten into a matrix formation as follows:

$$
\begin{gathered}
\dot{x}=P(x)+G u, \\
y=H x,
\end{gathered}
$$

where the state vector is

$$
x=\left[\delta_{i}, P_{i}, Q_{i}, \phi_{d i}, \phi_{q i}, \gamma_{d i}, \gamma_{q i}, i_{l d i}, i_{l q i}, v_{o d i}, v_{o q i}, i_{o d i}, i_{o q i}\right] .
$$

The detailed expression of $P(x), G$, and $H$ can be found in the Appendix. 


\section{Designing Decentralized Coordinated Controller by Feedback Linearization}

In this subsection, the hybrid multiagent consensus algorithm is used to control the amplitudes and angles of output voltages. To make amplitudes of output voltages follow the leader is considered the tracking synchronization problem and to make the angles of output voltages consensus is considered consensus regulation problem. Every DG can be seen as an agent with two control inputs and two outputs. The control signals are calculated by using the error between local and one of the neighbors information. The information about leader can come from one DG in the system.

In this section, the graph theory and feedback linearization designation based on the multiagent protocol are illustrated, respectively.

3.1. Graph Theory. The decentralized coordinated controller should use a communication network called directed graph which can be expressed as $G_{r}=\left(V_{G}, E_{G}, A_{G}\right)$ [23]. The set of nodes in the network can be expressed as $V_{G}=\left\{v_{1}, v_{2}, \ldots, v_{n}\right\}$, the set of edges can be expressed as $E_{G} \subseteq V_{G} \times V_{G}$, and the weighted adjacency matrix can be expressed as $A_{G}=\left[a_{i j}\right]_{n \times n}$ with nonnegative adjacency element $a_{i j}$. An edge rooted at node $j$ and ended at node $i$ is denoted by $\left(v_{j}, v_{i}\right)$, which means that information can be acquired from node $j$ to node $i$. For a graph with $0-1$ adjacency elements, the in-degree and outdegree of node $v_{i}$ are defined as

$$
\operatorname{deg}_{\text {in }}\left(v_{i}\right)=\sum_{j=1}^{n} a_{j i} \quad \operatorname{deg}_{\text {out }}\left(v_{i}\right)=\sum_{j=1}^{n} a_{i j} .
$$

The degree matrix of diagraph $G_{r}$ is a diagonal matrix $\Delta=$ $\left[\Delta_{i j}\right]$, where $\Delta_{i j}=0$ for all $i \neq j$ and $\Delta_{i i}=\operatorname{deg}_{\text {out }}\left(v_{i}\right)$. The graph Laplacian associated with the digraph $G_{r}$ is defined as

$$
L\left(G_{r}\right)=\Delta-A_{G} \text {. }
$$

3.2. Designation of Feedback Linearization. The $\delta_{\text {set } i}$ and $v_{\text {set } i}$ are selected as the control inputs to keep the angle $\delta_{i}$ and the amplitude $v_{o i}$ of the $i$ th DG consensus. Because $v_{o q i}$ is zero, the amplitude of output voltage is

$$
v_{o i}=v_{o d i}
$$

The inputs of the system are $u=\left[\begin{array}{ll}\delta_{\text {set } i} & v_{\text {set } i}\end{array}\right]^{T}$ and the outputs of the system are $y=\left[\begin{array}{ll}\delta_{i} & v_{\text {odi }}\end{array}\right]^{T}$. From the above discussion, the model established is a MIMO nonlinear system. Then the feedback linearization method is used to design the decentralized coordinated controller.

The $\delta_{\text {set } i}$ is used as the input to control angles of all output voltages to be consensus between DGs and the $v_{\text {set } i}$ is used as the input to control the amplitude of output voltage to be consensus with the leader's voltage $y_{\text {leader }, 2} \equiv v_{\text {ref }}$.

Because it is difficult to find the relationship between input and output directly in such a nonlinear system, the input-output feedback linearization is used to transform the nonlinear system into linear system and find the relationship.
The process of feedback linearization in this MIMO nonlinear system described in (15) is as follows [24]. lated.

First, the relative degree $\left[r_{1}, r_{2}, \ldots, r_{m}\right]$ should be calcu-

The control variables are shown up after one derivative of output; thus, the relative degree of this nonlinear system is $[1,1]$.

Second, according to the relative degree, a decoupling matrix $A(x)$ which should be nonsingular should be calculated as given in (20) and another vector $b(x)$ is calculated at the same time as in (21). The $L_{f} h_{i}(x)$ in (20) and (21) is the Lie derivative of $h_{i}(x)$ with the respect to $f$ and is defined as $L_{f} h_{i}(x)=\left(\partial\left(h_{i}\right) / \partial x_{i}\right) f$.

Consider

$$
\begin{aligned}
& A(x)=\left(\begin{array}{ccc}
L_{g_{1}} L_{f}^{r_{1}-1} h_{1}(x) & \cdots & L_{g_{m}} L_{f}^{r_{1}-1} h_{1}(x) \\
\vdots & & \vdots \\
L_{g_{1}} L_{f}^{r_{1}-1} h_{m}(x) & \cdots & L_{g_{m}} L_{f}^{r_{1}-1} h_{m}(x)
\end{array}\right), \\
& b(x)=\left[L_{f}^{r_{1}} h_{1}(x) \cdots L_{f}^{r_{m}} h_{m}(x)\right]^{T} .
\end{aligned}
$$

Because the relative degree of this nonlinear system is $[1,1]$, the decoupling matrix is calculated as

$$
A_{i}(x)=\left(\begin{array}{cc}
L_{g_{1}} L_{f}^{0} h_{1} & L_{g_{2}} L_{f}^{0} h_{1} \\
L_{g_{1}} L_{f}^{0} h_{2} & L_{g_{2}} L_{f}^{0} h_{2}
\end{array}\right)=\left(\begin{array}{cc}
\omega_{c i} \delta_{\text {set } i} & 0 \\
0 & \omega_{c i} V_{\text {set } i}
\end{array}\right) .
$$

It is obvious that matrix $A_{i}(x)$ is nonsingular. Additionally, matrix $b_{i}(x)$ is given as

$$
b_{i}(x)=\left[\begin{array}{lll}
L_{f} h_{1}(x) & L_{f} h_{2}(x)
\end{array}\right]^{T}
$$

where

$$
\begin{aligned}
L_{f} h_{1}(x)= & \omega_{i}+\omega_{c i}\left(\delta_{\text {set } i}-\delta_{i}^{*}\right)-m_{i} \omega_{c i} \widetilde{p}_{i} \\
L_{f} h_{2}(x)= & \omega_{c i}\left(v_{\text {set } i}-v_{o d i}^{*}\right)+n_{i} \omega_{c i} \widetilde{q}_{i}+\omega_{i} v_{o q i} \\
& +\frac{1}{C_{f i}}\left(i_{l d i}-i_{\text {odi }}\right) .
\end{aligned}
$$

Third, the control law of a MIMO nonlinear system is defined as

$$
u(x)=A^{-1}(x)[-b(x)+v(x)]
$$

where $v(x)=\left[v_{1} \cdots v_{m}\right]^{T}=\left[y_{1}^{\left(r_{1}\right)} \cdots y_{m}^{\left(r_{m}\right)}\right]^{T}$.

From (22) and (23), the control law $u_{i}(x)$ can be defined as in (25). The appropriate $v_{i}(x)$ can be calculated as in (26) to provide the synchronization:

$$
v_{i}(x)=A_{i}(x) u_{i}(x)+b_{i}(x)
$$

where $v_{i}=\left[\begin{array}{ll}v_{i, 1} & v_{i, 2}\end{array}\right]^{T}$.

The nonlinear system can be transformed into linear system as

$$
\left(\begin{array}{l}
\dot{y}_{i, 1} \\
\dot{y}_{i, 2}
\end{array}\right)=\left(\begin{array}{ll}
1 & 0 \\
0 & 1
\end{array}\right)\left(\begin{array}{l}
v_{i, 1} \\
v_{i, 2}
\end{array}\right),
$$

where $y_{i}=\left[\begin{array}{ll}y_{i, 1} & y_{i, 2}\end{array}\right]^{T}, y_{i, 1}=\delta_{i}$, and $y_{i, 2}=v_{o d i}$, for all $i$. 
Using the feedback linearization, the nonlinear system (15) is transformed to the linear system (27). Equation (27) presents the $i$ th DG. It is obvious that the $v_{i, 1}$ and $v_{i, 2}$ can be designed, respectively.

From Section 3.1, DGs can communicate with their neighbors based on the digraph $G_{r}$ and in this paper only one can communicate with the leader. The hybrid consensus algorithm consists of two kinds of consensus algorithms. One of the algorithms is called leaderless consensus algorithm which is used to control the angles of output voltages and the other one of the algorithm is called leader consensus algorithm which is used to control the amplitudes of output voltages.

The control of the angles from DGs is a consensus regulation problem which means the leaderless consensus algorithm is used. Thus, the errors about the angles between the DGs can be calculated as

$$
e_{i, 1}=\sum_{j \in N_{i}} a_{i j}\left(y_{i, 1}-y_{j, 1}\right)
$$

where $e_{i, 1}$ represents the error of angles of output voltage about the $i$ th DG.

To make all of the amplitude of output voltages equal to the leader's information, the tracking error about the amplitude of the output voltage and the reference information $y_{\text {leader, } 2}$ is given as

$$
e_{i, 2}=\sum_{j \in N_{i}} a_{i j}\left(y_{i, 2}-y_{j, 2}\right)+\varepsilon_{i, 2}\left(y_{i, 2}-y_{\text {leader }, 2}\right),
$$

where $e_{i, 2}$ represents the error of amplitudes of output voltage about the $i$ th DG. If node $i$ observes the leader's amplitude information, edge $\left(v_{\text {leader, } 2}, v_{i}\right)$ is said to exist with weighting gain $\varepsilon_{i, 2}=1$. Denote the pinning matrix by $E_{2}=\operatorname{diag}\left\{\varepsilon_{i, 2}\right\} \in$ $R^{N \times N}$.

Because a microgrid includes $N$ DGs, the errors can be written into matrix as

$$
\begin{gathered}
\mathbf{e}_{1}=\left(L+E_{1}\right) Y_{1}, \\
\mathbf{e}_{2}=\left(L+E_{2}\right)\left(Y_{2}-Y_{\text {leader }, 2}\right),
\end{gathered}
$$

where

$$
\begin{aligned}
\mathbf{e}_{1} & =\left[\begin{array}{llll}
e_{1,1} & e_{2,1} & \cdots & e_{n, 1}
\end{array}\right]^{T}, \\
\mathbf{e}_{2} & =\left[\begin{array}{llll}
e_{1,2} & e_{2,2} & \cdots & e_{n, 2}
\end{array}\right]^{T}, \\
Y_{1} & =\left[\begin{array}{llll}
y_{1,1} & y_{2,1} & \cdots & y_{n, 1}
\end{array}\right]^{T}, \\
Y_{2} & =\left[\begin{array}{llll}
y_{1,2} & y_{2,2} & \cdots & y_{n, 2}
\end{array}\right]^{T}, \\
Y_{\text {leader }, 2} & =1_{N} y_{\text {leader }, 2} .
\end{aligned}
$$

The system (28) can be rewritten as

$$
\begin{aligned}
& \dot{Y}_{1}=I_{N} \mathbf{v}_{1}, \\
& \dot{Y}_{2}=I_{N} \mathbf{v}_{2},
\end{aligned}
$$

where $\mathbf{v}_{1}=\left[\begin{array}{llll}v_{1,1} & v_{2,1} & \cdots & v_{n, 1}\end{array}\right]^{T}, \mathbf{v}_{2}=\left[\begin{array}{llll}v_{1,2} & v_{2,2} & \cdots & v_{n, 2}\end{array}\right]^{T}$.
The relationship between $\mathbf{e}_{1}, \mathbf{e}_{2}$ and $\mathbf{v}_{1}, \mathbf{v}_{2}$ should be designed in order to keep the system stable with the control input. The relationship can be established by the coupling gain and the feedback control gain. The design of the coupling gain and feedback control gain can be chosen according to the theory about optimal and nonlinear control in [24]. For the sake of space, the designation of the feedback control gain and coupling gain is not included in this paper.

In this paper, only the stability of the system (33) is proved as follows.

Proof. Because the angle controller is the same as the amplitude controller, if one of the controllers is proved to be stable, the other one should be stable. In this section, the $\dot{Y}_{2}=I_{N} \mathbf{v}_{2}$ is proved to be stable under some conditions.

Inserting (31) into (33), the system can be as

$$
\dot{Y}_{2}=-c k\left(L+E_{2}\right)\left(Y_{2}-Y_{\text {leader }, 2}\right) .
$$

Defining $\delta_{2}=Y_{2}-Y_{\text {leader }, 2}$, choose the Lyapunov function as

$$
V=\frac{1}{2} \delta_{2}^{T} P \delta_{2}
$$

where $P^{T}=P$ and $P$ is the positive and definite matrix. Then the derivative of (35) is expressed as

$$
\dot{V}=\delta_{2}^{T} P \dot{\delta}_{2}=\delta_{2}^{T} P\left(\dot{Y}_{2}-\dot{Y}_{\text {leader }, 2}\right) \text {. }
$$

Then,

$$
\dot{V}=\delta_{2}^{T} P \dot{\delta}_{2}=\delta_{2}^{T} P\left(-c k\left(L+E_{2}\right)\right) \delta_{2} .
$$

Then, according to [25], the matrix $-c k\left(L+E_{2}\right)$ can be Hurwitz. Therefore, given any positive number $\mu$, the positive definite matrix $P$ can be chosen as

$$
P\left(-c k\left(L+E_{2}\right)\right)+\left(-c k\left(L+E_{2}\right)\right)^{T} P=-\mu I_{N} .
$$

Then, inserting (38) into (37),

$$
\begin{aligned}
\dot{V} & =\delta_{2}^{T} P \dot{\delta}_{2} \\
& =\frac{1}{2} \delta_{2}^{T}\left(P\left(-c k\left(L+E_{2}\right)\right)+\left(-c k\left(L+E_{2}\right)\right)^{T} P\right) \delta_{2} \\
& =-\frac{\mu}{2} \delta_{2}^{T} I_{N} \delta_{2} .
\end{aligned}
$$

Then, (39) shows that $\dot{V} \leq 0$. Thus, the internal dynamics are asymptotically stable. The proof is completed.

\section{Circulating Current Analysis}

In order to illustrate the effectiveness of proposed method focusing on the problem of circulating current between inverters, the relationship between a circulating current and amplitude and angle of output voltage is analyzed in this section. The simplified circuit schematic is shown in Figure 6. 


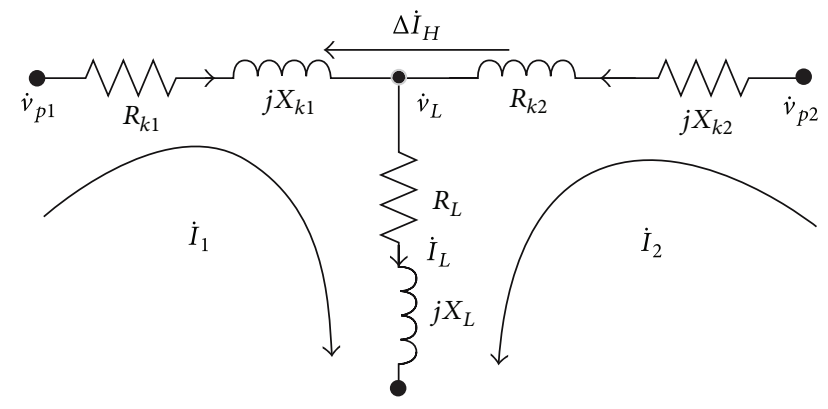

FIGURE 6: Simplified circuit diagram for two inverters.

From the circuit scheme, the following circuit equations can be expressed for two inverters:

$$
\begin{gathered}
\dot{I}_{L}=\dot{I}_{1}+\dot{I}_{2}, \\
\dot{v}_{L}=Z_{L}\left(\dot{I}_{1}+\dot{I}_{2}\right), \\
\dot{I}_{1}=\frac{\dot{v}_{p 1}-\dot{v}_{L}}{Z_{k 1}}, \\
\dot{I}_{2}=\frac{\dot{v}_{p 2}-\dot{v}_{L}}{Z_{k 2}},
\end{gathered}
$$

where $\dot{v}_{p 1}=E_{1} \angle \phi_{1}, \dot{v}_{p 2}=E_{2} \angle \phi_{2}, Z_{L}=R_{L}+j X_{L}, Z_{k 1}=$ $R_{k 1}+j X_{k 1}$, and $Z_{k 2}=R_{k 2}+j X_{k 2}$.

The load current is the phasor summation of the current of all the parallel inverters as given in (41). The load voltage is related to the load current and the impedance of load. From (41)-(44), the bus voltage of load $\dot{v}_{L}$ can be presented as

$$
\dot{v}_{L}=Z_{L}\left(\frac{\dot{v}_{p 1}-\dot{v}_{L}}{Z_{k 1}}+\frac{\dot{v}_{p 2}-\dot{v}_{L}}{Z_{k 2}}\right)=\frac{Z_{k 1} \dot{v}_{p 2}+Z_{k 2} \dot{v}_{p 1}}{Z_{k 1}+Z_{k 2}+Z_{k 1} Z_{k 2} / Z_{L}} .
$$

The circulating current between two inverters is equal to half of the difference current given in

$$
2 \Delta \dot{I}_{H}=\dot{I}_{1}-\dot{I}_{2}=\frac{\dot{v}_{p 1}-\dot{v}_{L}}{Z_{k 1}}-\frac{\dot{v}_{p 2}-\dot{v}_{L}}{Z_{k 2}} .
$$

Inserting (45) into (46), the current can be presented by using the angle and amplitude of output voltage from inverters as

$$
2 \Delta \dot{I}_{H}=\frac{2\left(\dot{v}_{p 1}-\dot{v}_{p 2}\right)+\left(Z_{k 2} \dot{v}_{p 1}-Z_{k 1} \dot{v}_{p 2}\right) / Z_{L}}{Z_{k 1}+Z_{k 2}+Z_{k 1} Z_{k 2} / Z_{L}} .
$$

Assuming that the equivalent load impedance of bus is resistive, the impedance $Z_{L}$ is replaced by $R_{L}$. Meanwhile, even though it is a microgrid in a small area, it is reasonable to illustrate that the impedance of the connection between inverters is inductive through designing the inductive virtual impedance [15]; in this paper, it is not discussed in detail. Thus, it means that $X_{k} \gg R_{k}$; then the circulating current is given as follows:

$$
2 \Delta \dot{I}_{H}=\frac{2\left(\dot{v}_{p 1}-\dot{v}_{p 2}\right)+j\left(X_{k 2} \dot{v}_{p 1}-X_{k 1} \dot{v}_{p 2}\right) / R_{L}}{j\left(X_{k 1}+X_{k 2}\right)-X_{k 1} X_{k 2} / R_{L}} .
$$

In order to analyze the active and reactive circulating current, respectively, (48) is decomposed into two parts as

$$
2 \Delta \dot{I}_{H}=I_{a}-j I_{r} .
$$

For convenience, the following variables are defined:

$$
\begin{gathered}
E_{1}^{\prime}=\frac{X_{k 2}}{R_{L}} E_{1}, \quad E_{2}^{\prime}=\frac{X_{k 1}}{R_{L}} E_{2}, \\
A=\left(X_{k 1}+X_{k 2}\right)^{2}+\left(\frac{X_{k 1} X_{k 2}}{R_{L}}\right)^{2}, \\
B=\frac{X_{k 1} X_{k 2}^{2}+2 R_{L}^{2} X_{k 1}+2 R_{L}^{2} X_{k 2}}{R_{L} X_{k 2}}, \\
C=\frac{X_{k 2} X_{k 1}^{2}+2 R_{L}^{2} X_{k 2}+2 R_{L}^{2} X_{k 1}}{R_{L} X_{k 1}} .
\end{gathered}
$$

Then active and reactive current between inverters can be presented, respectively, as follows:

$$
\begin{aligned}
I_{a}=( & E_{1}^{\prime}\left[\left(X_{k 2}-X_{k 1}\right) \cos \phi_{1}+B \sin \phi_{1}\right] \\
& \left.-E_{2}^{\prime}\left[\left(X_{k 1}-X_{k 2}\right) \cos \phi_{2}+C \sin \phi_{2}\right]\right)(A)^{-1}, \\
I_{r}=( & E_{1}^{\prime}\left[\left(X_{k 1}-X_{k 2}\right) \sin \phi_{1}+B \cos \phi_{1}\right] \\
& \left.-E_{2}^{\prime}\left[\left(X_{k 2}-X_{k 1}\right) \sin \phi_{2}+C \cos \phi_{2}\right]\right)(A)^{-1} .
\end{aligned}
$$

In order to analyze the circulating current, it is assumed that $X_{k 1}=X_{k 2}=X_{k}$ and then (51) and (52) can be rewritten as

$$
\begin{aligned}
& I_{a}=\frac{\left(\left(X_{k}^{2}+4 R_{L}^{2}\right) / R_{L}\right)\left(E_{1}^{\prime} \sin \phi_{1}-E_{2}^{\prime} \sin \phi_{2}\right)}{A}, \\
& I_{r}=\frac{\left(\left(X_{k}^{2}+4 R_{L}^{2}\right) / R_{L}\right)\left(E_{1}^{\prime} \cos \phi_{1}-E_{2}^{\prime} \cos \phi_{2}\right)}{A} .
\end{aligned}
$$

From (52) and (53), it is found that if the amplitude and angle of output voltage can be kept as consensus, the active and reactive current can be suppressed effectively. Thus, the proposed method can suppress the circulating current.

\section{Simulation Results}

Figure 7 shows the diagram of the typical microgrid test system. The configuration of DGs which are connected in series is considered in this microgrid. Because it is the typical microgrid system, the simulation results can be more convincing. The system data and simulation parameters are listed in Table 1. It is assumed that the total power demand in the microgrid can be supplied by the DGs and no load shedding is required.

5.1. Case 1: Conventional Controller. In this case, the desired active and reactive ratio of DG-1, DG-2, and DG-3 is $1: 1.33: 2$. The DG-1 is chosen as the system leader. The simulation 


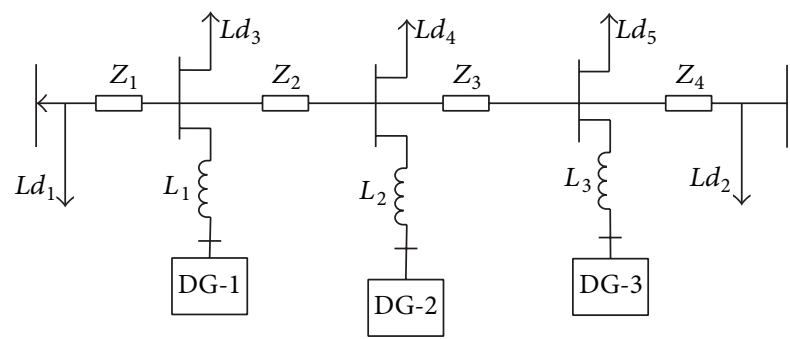

FIGURE 7: Diagram of the microgrid test system.

TABLE 1: System parameters.

\begin{tabular}{|c|c|}
\hline System quantities & Values \\
\hline System frequency & $50 \mathrm{~Hz}$ \\
\hline DC voltage & $600 \mathrm{~V}$ \\
\hline \multicolumn{2}{|l|}{ Leader information } \\
\hline Voltage & 1p.u. \\
\hline \multicolumn{2}{|l|}{ Line impedance } \\
\hline$Z_{1}=Z_{2}=Z_{3}=Z_{4}$ & $0.74+j 2.4 * 10^{-4} \Omega$ \\
\hline \multicolumn{2}{|l|}{ Load ratings } \\
\hline$L d_{1}$ & $10 \mathrm{KW}$ and $6 \mathrm{kVAr}$ \\
\hline$L d_{2}$ & $11.1 \mathrm{KW}$ and $7 \mathrm{kVAr}$ \\
\hline$L d_{3}$ & $10.1 \mathrm{KW}$ and $5 \mathrm{kVAr}$ \\
\hline$L d_{4}$ & $9.1 \mathrm{KW}$ and $5 \mathrm{kVAr}$ \\
\hline$L d_{5}$ & $11.1 \mathrm{KW}$ and $5 \mathrm{kVAr}$ \\
\hline \multicolumn{2}{|l|}{ DG ratings } \\
\hline DG-1 & $20 \mathrm{KW}$ and $10 \mathrm{kVAr}$ \\
\hline DG-2 & 26.6 KW and $13.2 \mathrm{kVAr}$ \\
\hline DG-3 & $40 \mathrm{KW}$ and $20 \mathrm{kVAr}$ \\
\hline \multicolumn{2}{|l|}{ Output inductances } \\
\hline$L_{1}$ & $30 \mu \mathrm{H}$ \\
\hline$L_{2}$ & $22.53 \mu \mathrm{H}$ \\
\hline$L_{4}$ & $15 \mu \mathrm{H}$ \\
\hline \multicolumn{2}{|l|}{ Droop coefficients } \\
\hline \multicolumn{2}{|l|}{ Active power-angle } \\
\hline$m_{1}$ & $2 * 10^{-4} \mathrm{rad} / \mathrm{w}$ \\
\hline$m_{2}$ & $1.5 * 10^{-4} \mathrm{rad} / \mathrm{w}$ \\
\hline$m_{3}$ & $1 * 10^{-4} \mathrm{rad} / \mathrm{w}$ \\
\hline \multicolumn{2}{|l|}{ Reactive power-voltage } \\
\hline$n_{1}$ & $1 * 10^{-4} \mathrm{rad} / \mathrm{VAr}$ \\
\hline$n_{2}$ & $0.75 * 10^{-4} \mathrm{rad} / \mathrm{VAr}$ \\
\hline$n_{3}$ & $0.5 * 10^{-4} \mathrm{rad} / \mathrm{VAr}$ \\
\hline
\end{tabular}

process is as follows which is divided into 4 steps: first, at the beginning, load , load $_{3}$, load $_{4}$, and load 5 are connected in the microgrid; second, at $0.3 \mathrm{~s}, \operatorname{load}_{2}$ is connected in the microgrid; third, at $0.6 \mathrm{~s}, \operatorname{load}_{1}$ and load ${ }_{5}$ are disconnected from the system; fourth, at $0.8 \mathrm{~s}, \operatorname{load}_{5}$ is connected in the microgrid again. The load power is shared by DG-1, DG-2, and DG-3 all the time. The system can be operated stably.

However, due to the weak controller, from $0.3 \mathrm{~s}$ to $1 \mathrm{~s}$, the load cannot be shared in the desired ratio of $1: 1.33: 2$ as shown in Figures 8 and 9. Meanwhile, the amplitudes and angles of output voltage from different DGs cannot be kept as

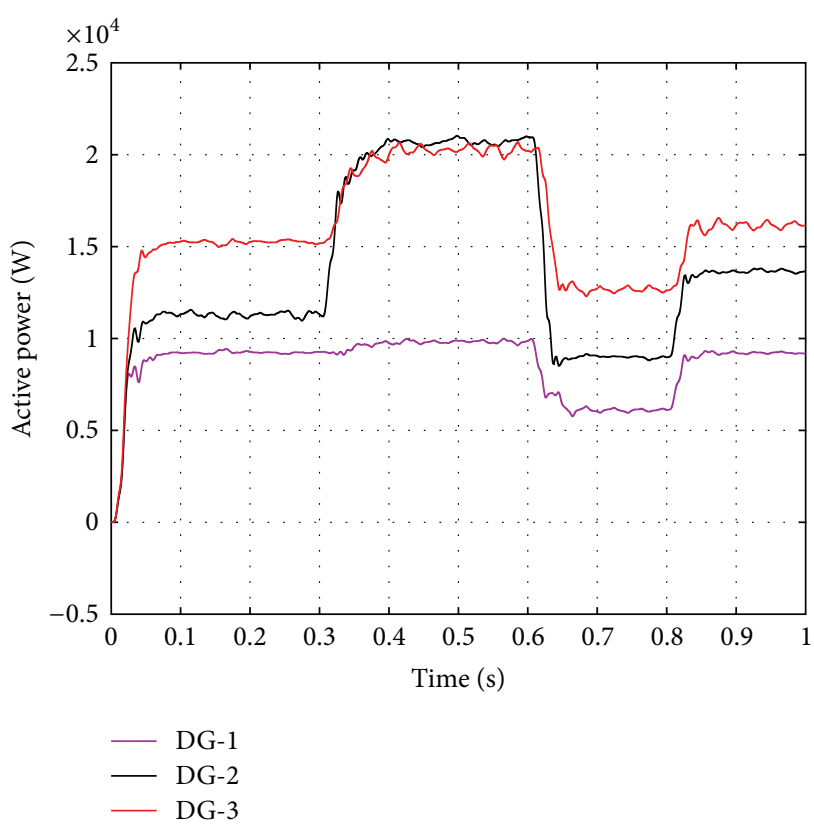

Figure 8: Active power sharing in Case 1.

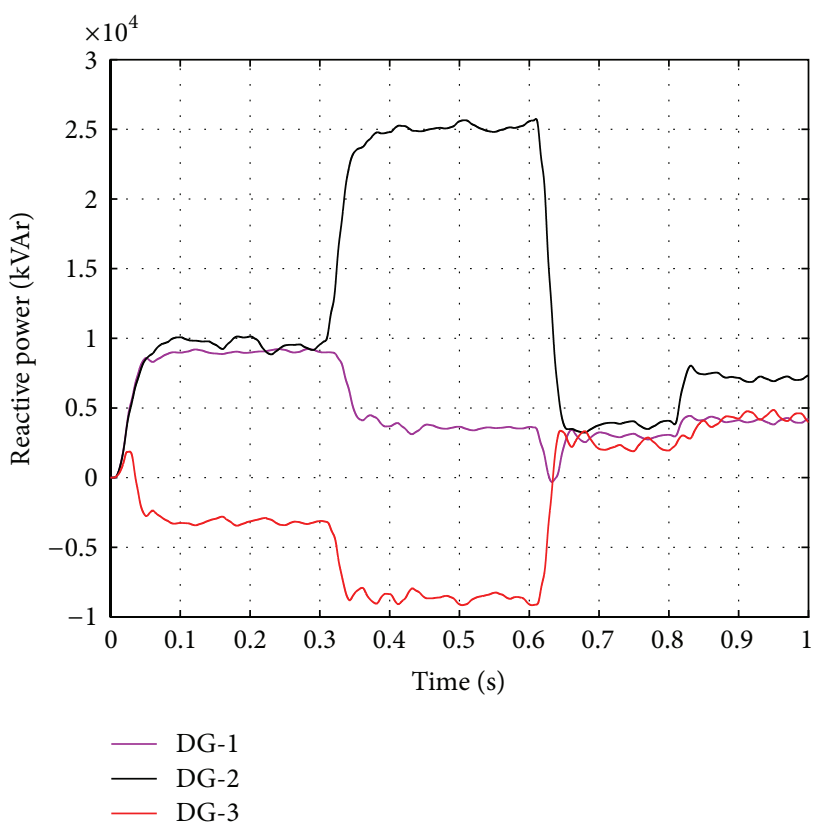

FIgURE 9: Reactive power sharing in Case 1.

consensus as shown in Figures 10 and 11. Because the power cannot be shared in the desired ratio shown in Figures 8 and 9, the amplitudes of output voltages are not in the desired ratio and the deviation angles between four outputs voltages are obvious, as shown in Figures 10 and 11. Thus, the circulating currents between DGs are very large in the system. In order to illustrate the problem of the conventional controller, Figure 11 is partially enlarged from $0.2 \mathrm{~s}$ to $1 \mathrm{~s}$, which is overlaid on the low left of the original figures. 


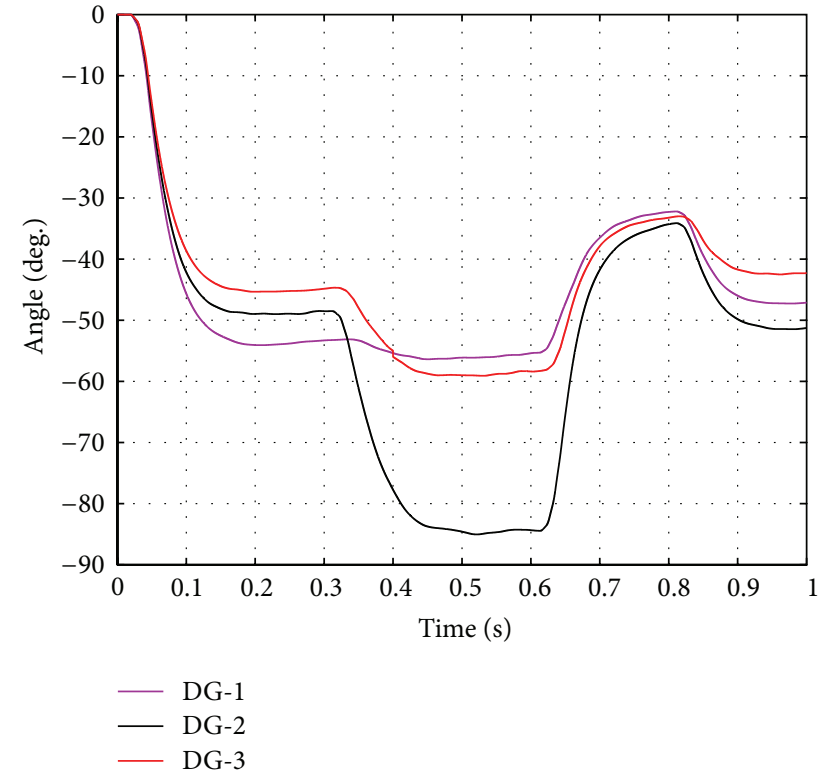

FIgURE 10: Angles of output voltages from 4 DGs in Case 1.

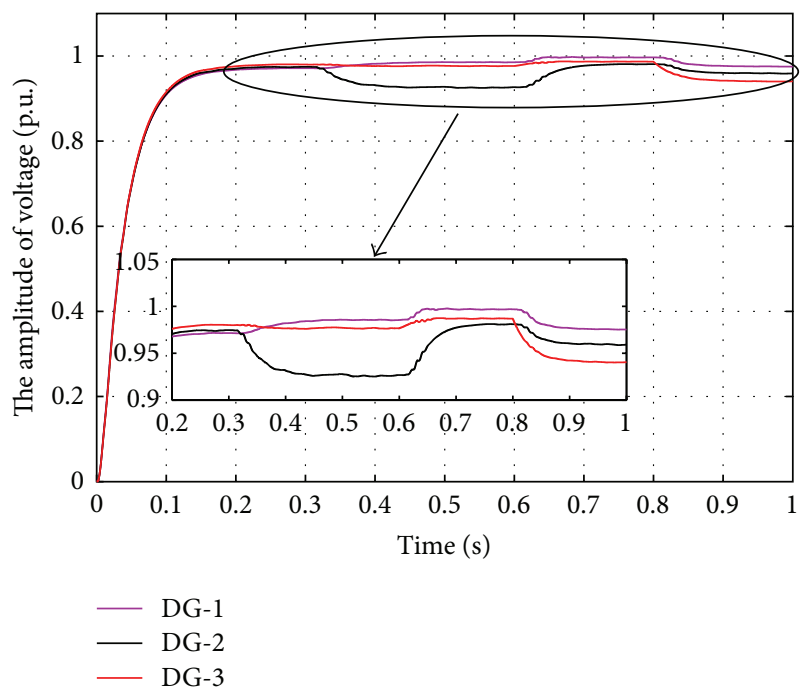

FIGURE 11: The p.u. value of output voltages from 4 DGs in Case 1.

5.2. Case 2: Proposed Controller. The performance of the proposed controller can be verified though the simulation in Case 2. In order to compare with the simulation results in Case 1, the microgrid is operated at similar situation as described in Case 1. The proposed controller is started at $0.2 \mathrm{~s}$ and the communication topology is shown in Figure 12. Compared with results in Case 1, the load can be shared in the desired ratio by DGs as shown in Figures 13 and 14. The amplitudes can be controlled to track with the leader's information and the angles of output from DGs can be kept as consensus as shown in Figures 15 and 16, respectively. Meanwhile, the deviation angles between four output voltages are very small as shown in Figure 15. From the discussion in Section 4, the circulating current between DGs can be

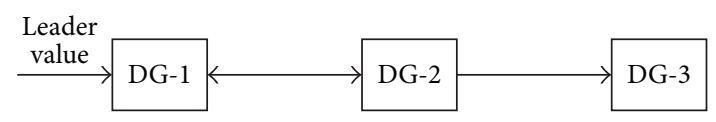

FIGURE 12: The communication topology for proposed controller.

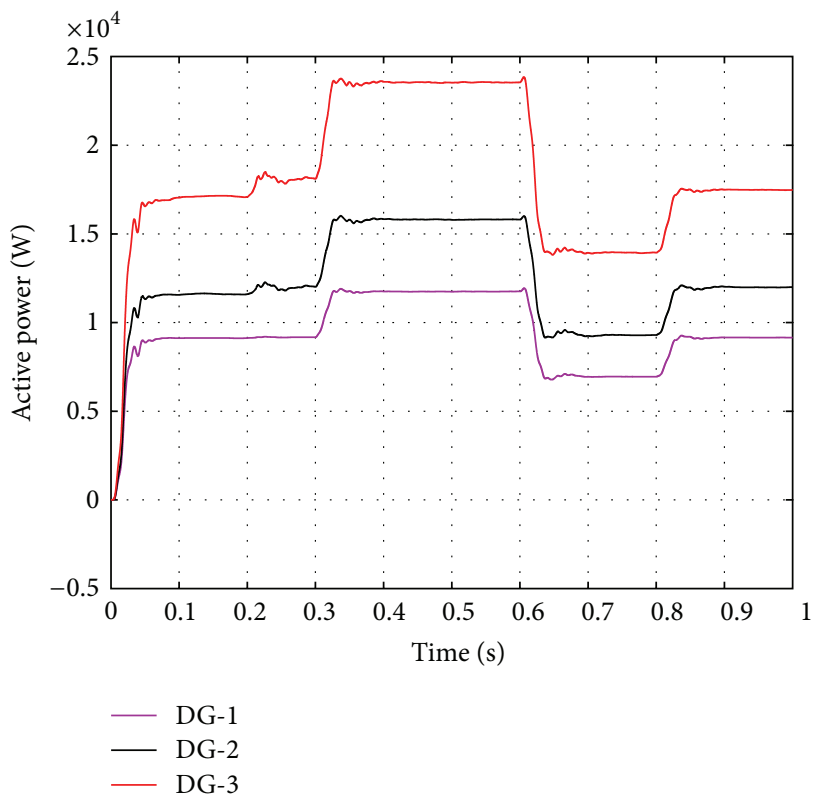

FIgURE 13: Active power sharing in Case 2.

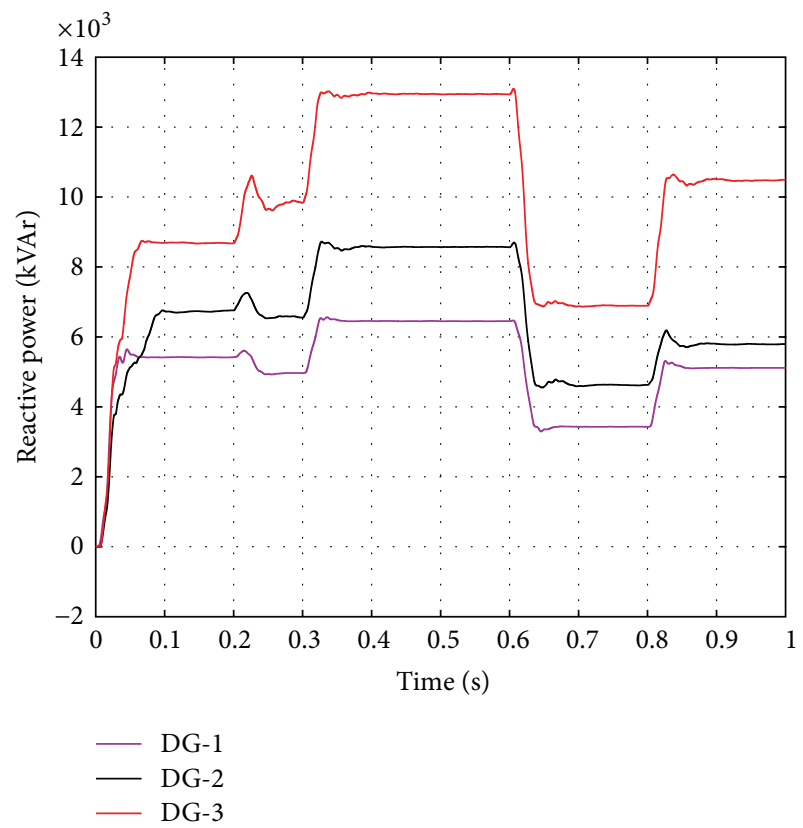

FIgURE 14: Reactive power sharing in Case 2.

reduced largely. In addition, from Figures 15 and 16, it can also be concluded that the amplitude of output voltage can track the leader quickly. In addition, when the amplitudes of voltage are consensus, the power flow can be shared more reasonably. In order to illustrate the effectiveness of the proposed controller, Figure 16 is partially enlarged from 


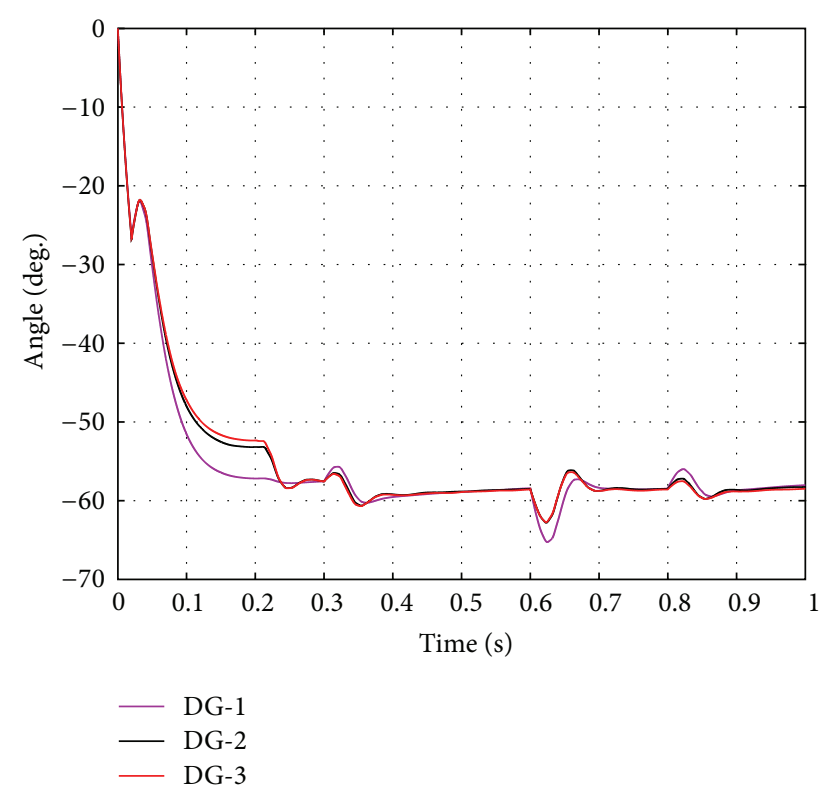

Figure 15: Angles of output voltages from 4 DGs in Case 2.

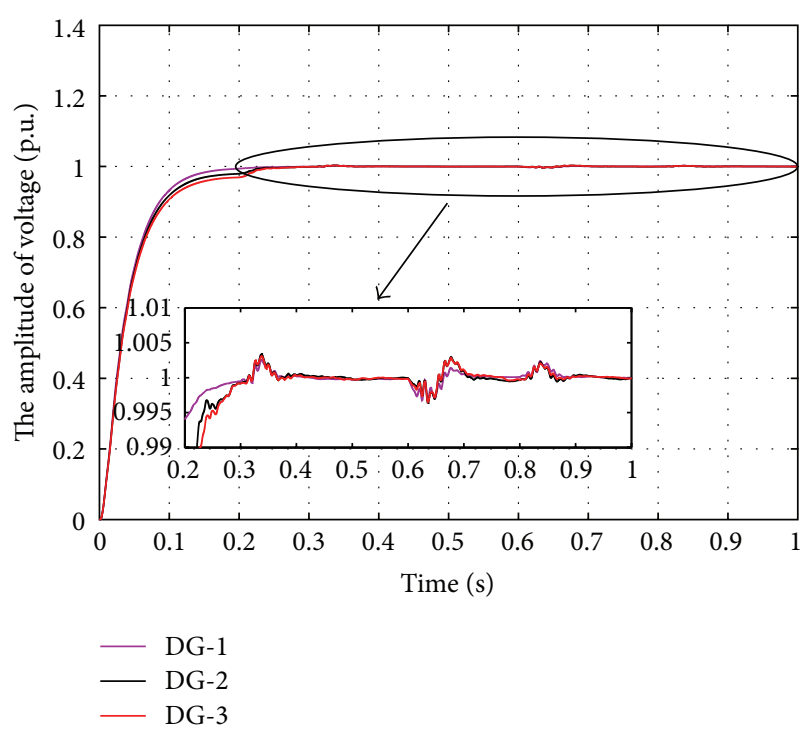

FIGURE 16: The p.u. value of output voltages from 4 DGs in Case 2.

$0.2 \mathrm{~s}$ to $1 \mathrm{~s}$, which is overlaid on the low left of the original figures.

Meanwhile, from Case 2, it can be proved that the proposed controller can make the amplitude of output voltages keep tracking with the leader and make angles of output voltages kept as consensus.

\section{Conclusion}

The control issues of multiple inverters in the microgrid were investigated in this paper. The nonlinear mathematics model of inverters is discussed and the feedback linearization method is used to transform this nonlinear model into the linear model. The hybrid multiagent consensus algorithm is used to control the amplitudes and angles of output voltages. In general, this method can also be used in a kind of problems of the coordinated control. In this paper, the first benefit of the proposed method is that the circulating can be effectively suppressed and the power can be shared in the desired ratio through combining with the angle-active power droop controller and voltage-reactive droop controller. The second benefit is that, by using the hybrid multiagent consensus algorithm with the two kinds of consensus algorithm, the system can be controlled more reasonably and economically. The third benefit is that the distributed coordinated controller only requires local and one neighbor's information with sparse communication structure which can make the microgrid more reliable.

\section{Appendix}

Consider

$$
\begin{aligned}
& P(x)=\left(\begin{array}{c}
\omega_{c i} \tilde{p}_{i}+\frac{\omega_{i}}{m_{i}\left(\delta_{i}^{*}-\delta_{\text {set } i}\right)} \\
\omega_{c i} \tilde{q}_{i}+\frac{\omega_{c i}\left(v_{o d i}^{*}-v_{\text {set } i}\right)}{n_{i} Q_{i}-v_{o d i}} \\
v_{o q i}^{*}-v_{o q i} \\
i_{l d i}^{*}-i_{l d i} \\
i_{l q i}^{*}-i_{l q i} \\
-\frac{R_{f i}}{L_{f i}} i_{l d i}+\omega_{i} i_{l q i}+\frac{1}{L_{f i}}\left(v_{i d i}-v_{o d i}\right) \\
-\frac{R_{f i}}{L_{f i}} i_{l q i}-\omega_{i} i_{l d i}+\frac{1}{L_{f i}}\left(v_{i q i}-v_{o q i}\right) \\
\omega_{i} v_{o q i}+\frac{1}{C_{f i}}\left(i_{l d i}-i_{o d i}\right) \\
-\omega_{i} v_{o d i}+\frac{1}{C_{f i}}\left(i_{l q i}-i_{o q i}\right) \\
\omega_{i} i_{o q i}+\frac{1}{L_{c i}}\left(v_{o d i}-v_{b d i}\right)-\frac{R_{c i}}{L_{c i}} i_{o d i} \\
-\omega_{i} i_{o d i}+\frac{1}{L_{c i}}\left(v_{o q i}-v_{b q i}\right)-\frac{R_{c i}}{L_{c i}} i_{o q i}
\end{array}\right) \\
& G=\left(\begin{array}{ccccccccccccc}
0 & -\frac{\omega_{c i}}{m_{i}} & 0 & 0 & 0 & 0 & 0 & 0 & 0 & 0 & 0 & 0 & 0 \\
0 & 0 & -\frac{\omega_{c i}}{n_{i}} & 1 & 0 & 0 & 0 & 0 & 0 & 0 & 0 & 0 & 0
\end{array}\right)^{T} \\
& H=\left(\begin{array}{lllllllllllll}
1 & 0 & 0 & 0 & 0 & 0 & 0 & 0 & 0 & 0 & 0 & 0 & 0 \\
0 & 0 & 0 & 0 & 0 & 0 & 0 & 0 & 0 & 1 & 0 & 0 & 0
\end{array}\right) \text {. }
\end{aligned}
$$

\section{Conflict of Interests}

The authors declare that there is no conflict of interests regarding the publication of this paper. 


\section{Acknowledgments}

This work was supported by the Key Foundation of the National Natural Science Foundation of China (61433004) and the Young Foundation of National Natural Science Foundation of China (61203086).

\section{References}

[1] A. Bidram and A. Davoudi, "Hierarchical structure of microgrids control system," IEEE Transactions on Smart Grid, vol. 3, no. 4, pp. 1963-1976, 2012.

[2] A. Mehrizi-Sani and R. Iravani, "Potential-function based control of a microgrid in islanded and grid-connected modes," IEEE Transactions on Power Systems, vol. 25, no. 4, pp. 18831891, 2010.

[3] J. M. Guerrero, J. Matas, L. G. de Vicuña, M. Castilla, and J. Miret, "Decentralized control for parallel operation of distributed generation inverters using resistive output impedance," IEEE Transactions on Industrial Electronics, vol. 54, no. 2, pp. 994-1004, 2007.

[4] Q. Shafiee, J. C. Vasquez, and J. M. Guerrero, "Distributed secondary control for islanded microGrids-a networked control systems approach," in Proceedings of the 38th Annual Conference on IEEE Industrial Electronics Society (IECON '12), pp. 56375642, October 2012.

[5] J. M. Guerrero, J. C. Vasquez, J. Matas, L. G. de Vicuña, and M. Castilla, "Hierarchical control of droop-controlled AC and DC microgrids-a general approach toward standardization," IEEE Transactions on Industrial Electronics, vol. 58, no. 1, pp. 158-172, 2011.

[6] R. Majumder, B. Chaudhuri, A. Ghosh, R. Majumder, G. Ledwich, and F. Zare, "Improvement of stability and load sharing in an autonomous microgrid using supplementary droop control loop," IEEE Transactions on Power Systems, vol. 25, no. 2, pp. 796-808, 2010.

[7] J. M. Guerrero, L. G. de Vicuña, J. Matas, M. Castilla, and J. Miret, "A wireless controller to enhance dynamic performance of parallel inverters in distributed generation systems," IEEE Transactions on Power Electronics, vol. 19, no. 5, pp. 1205-1213, 2004.

[8] J. M. Guerrero, J. Matas, L. G. de Vicuña, M. Castilla, and J. Miret, "Wireless-control strategy for parallel operation of distributed-generation inverters," IEEE Transactions on Industrial Electronics, vol. 53, no. 5, pp. 1461-1470, 2006.

[9] J. M. Guerrero, L. G. de Vicuña, J. Matas, M. Castilla, and J. Miret, "Output impedance design of parallel-connected UPS inverters with wireless load-sharing control," IEEE Transactions on Industrial Electronics, vol. 52, no. 4, pp. 1126-1135, 2005.

[10] N. Pogaku, M. Prodanović, and T. C. Green, "Modeling, analysis and testing of autonomous operation of an inverter-based microgrid," IEEE Transactions on Power Electronics, vol. 22, no. 2, pp. 613-625, 2007.

[11] M. C. Chandorkar, D. M. Divan, and R. Adapa, "Control of parallel connected inverters in standalone ac supply systems," IEEE Transactions on Industry Applications, vol. 29, no. 1, pp. 136-143, 1993.

[12] M. C. Chandorkar, D. M. Divan, Y. Hu, and B. Banerjee, "Novel architectures and control for distributed UPS systems," in Proceedings of the 9th Annual Applied Power Electronics Conference and Exposition, pp. 683-689, February 1994.
[13] J. M. Guerrero, N. Berbel, L. G. de Vicuña, J. Matas, J. Miret, and M. Castilla, "Droop control method for the parallel operation of online uninterruptible power systems using resistive output impedance," in Proceedings of the 21st Annual IEEE Applied Power Electronics Conference and Exposition (APEC '06), pp. 1716-1722, March 2006.

[14] Z. Ye, P. K. Jain, and P. C. Sen, "Circulating current minimization in high-frequency AC power distribution architecture with multiple inverter modules operated in parallel," IEEE Transactions on Industrial Electronics, vol. 54, no. 5, pp. 26732687, 2007.

[15] Y. W. Li and C.-N. Kao, "An accurate power control strategy for power-electronics-interfaced distributed generation units operating in a low-voltage multibus microgrid," IEEE Transactions on Power Electronics, vol. 24, no. 12, pp. 2977-2988, 2009.

[16] J. M. Guerrero, J. C. Vasquez, J. Matas, M. Castilla, and L. G. de Vicuña, "Control strategy for flexible microgrid based on parallel line-interactive UPS systems," IEEE Transactions on Industrial Electronics, vol. 56, no. 3, pp. 726-736, 2009.

[17] J. E. Slotine and W. Li, Applied Nonlinear Control, Prentice-Hall, Upper Saddle River, NJ, USA, 2009.

[18] Y. Hong, J. Hu, and L. Gao, "Tracking control for multiagent consensus with an active leader and variable topology," Automatica, vol. 42, no. 7, pp. 1177-1182, 2006.

[19] L. Hongbo, Y. Jun, X. Jian, and S. Hongtao, "Single-phase inverter voltage control and parallel circulation current suppression," in Proceedings of the 6th IEEE International Power Electronics and Motion Control Conference (IPEMC '09), pp. 1564-1572, Wuhan, China, May 2009.

[20] R. Majumder, A. Ghosh, G. Ledwich, and F. Zare, "Load sharing and power quality enhanced operation of a distributed microgrid," IET Renewable Power Generation, vol. 3, no. 2, pp. 109-119, 2009.

[21] J. C. Vasquez, J. M. Guerrero, A. Luna, P. Rodríguez, and R. Teodorescu, "Adaptive droop control applied to voltage-source inverters operating in grid-connected and islanded modes," IEEE Transactions on Industrial Electronics, vol. 56, no. 10, pp. 4088-4096, 2009.

[22] M. Ciobotaru, R. Teodorescu, and F. Blaabjerg, "A new singlephase PLL structure based on second order generalized integrator," in Proceedings of the 37th IEEE Power Electronics Specialists Conference (PESC '06), pp. 1-6, June 2006.

[23] C. Godsil and G. Royle, Algebraic Graph Theory, Graduate Texts in Mathematics, Springer, 2001.

[24] F. L. Lewis and V. L. Syrmos, Optimal Control, John Wiley \& Sons, New York, NY, USA, 1995.

[25] H. Zhang, F. L. Lewis, and A. Das, "Optimal design for synchronization of cooperative systems: state feedback, observer and output feedback," IEEE Transactions on Automatic Control, vol. 56, no. 8, pp. 1948-1952, 2011. 


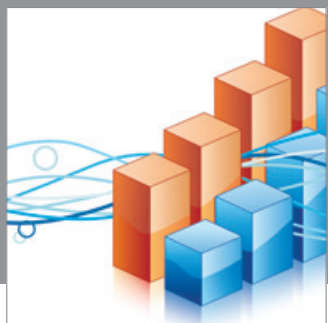

Advances in

Operations Research

mansans

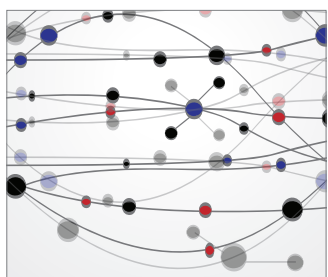

The Scientific World Journal
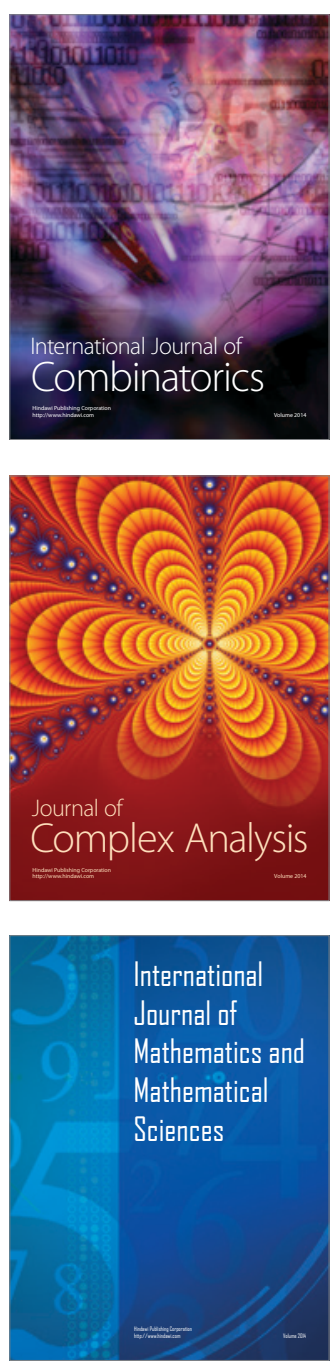
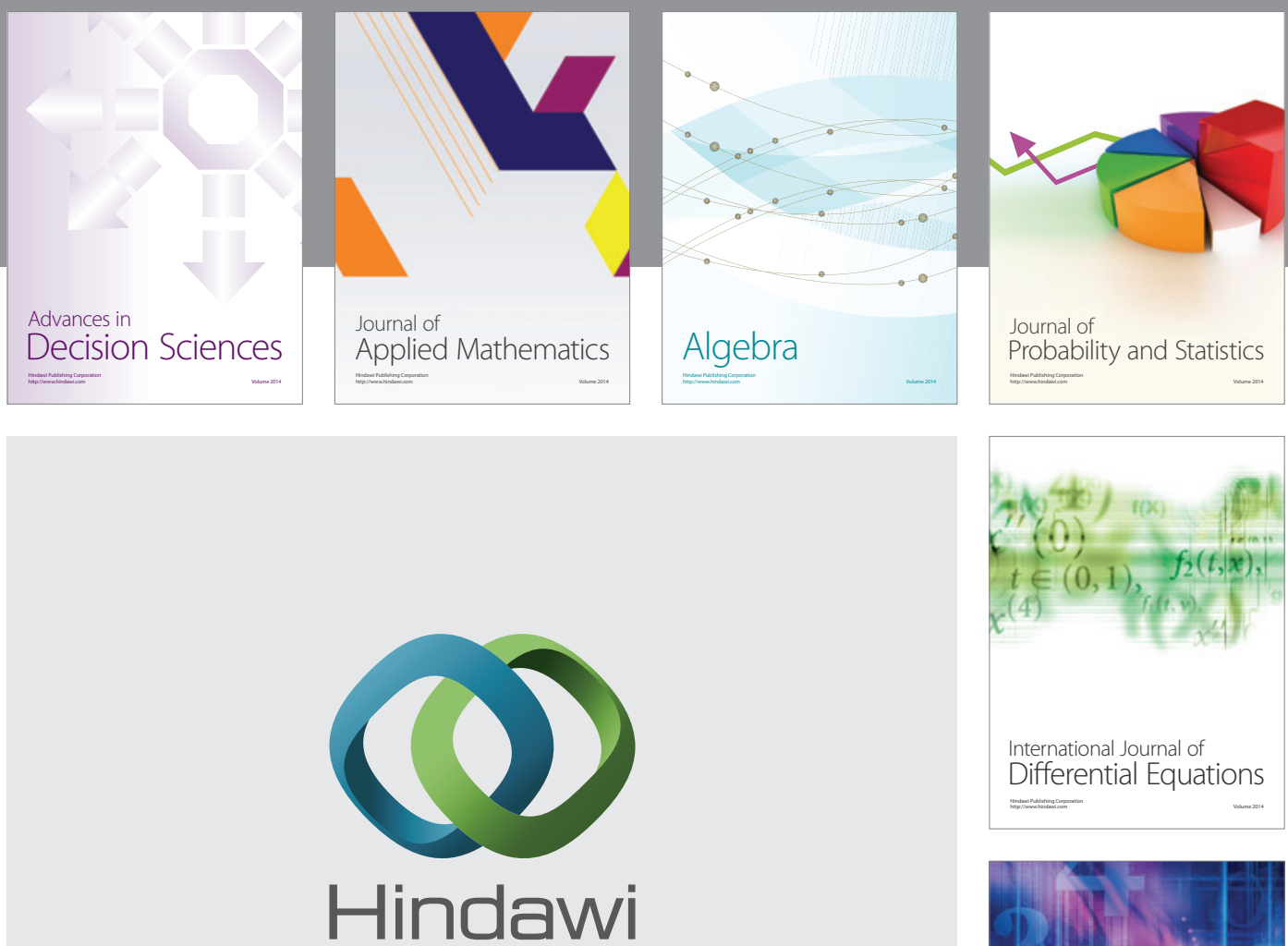

Submit your manuscripts at http://www.hindawi.com
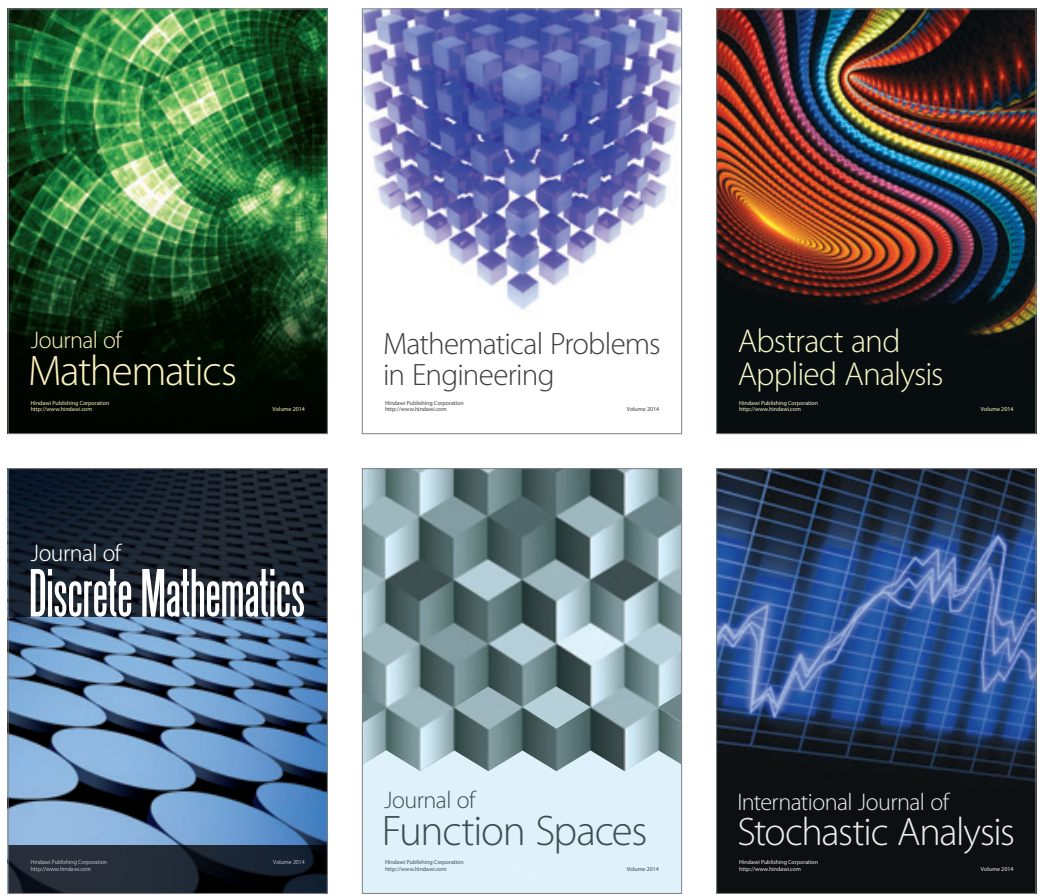

Journal of

Function Spaces

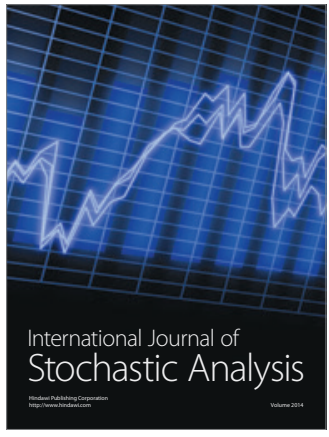

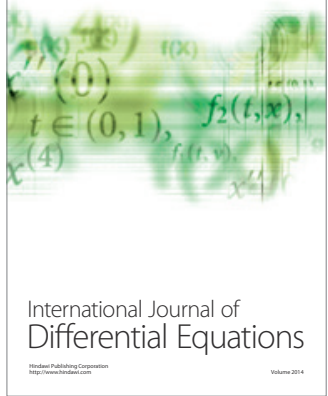
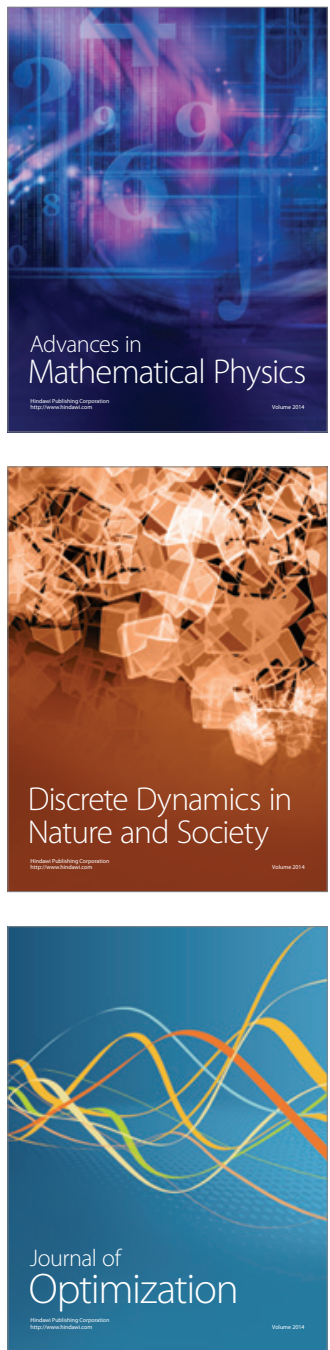